\title{
Elizabeth (Betsy) Nicholls (1946 - 2004)
}

Betsy was born in Berkeley, California (USA) and moved to Melbourne, Victoria (Australia) at the age of 10. Determined to be a palaeontologist from a young age, Betsy returned to California to do her undergraduate studies in the Department of Paleontology at the University of California, Berkeley. In 1969, she then moved to Calgary, Alberta (Canada) where she finished her $\mathrm{PhD}$ at the University of Calgary.

She began her career in Canada by discovering, collecting and studying the oldest known plesiosaur from North America, remains of which were found in the mountains southwest of Calgary. She became the marine reptile specialist at the Royal Tyrrell Museum in Drumheller, Alberta in 1990 and Curator of Marine Reptiles in 1991.

Betsy was one of Alberta's most accomplished vertebrate palaeontologists. She gained international recognition for discovering and describing new species of primitive marine reptiles from the Wapiti Lake region in British Columbia, a project that established Western Canada as an important world locale for Triassic reptiles. In 2000, she received the prestigious Rolex Award for her pivotal role in recovering the remains of a 23-metre-long ichthyosaur, a marine reptile found in the Pink Mountain region of British Columbia.

Jennifer Nicholls, April 2005

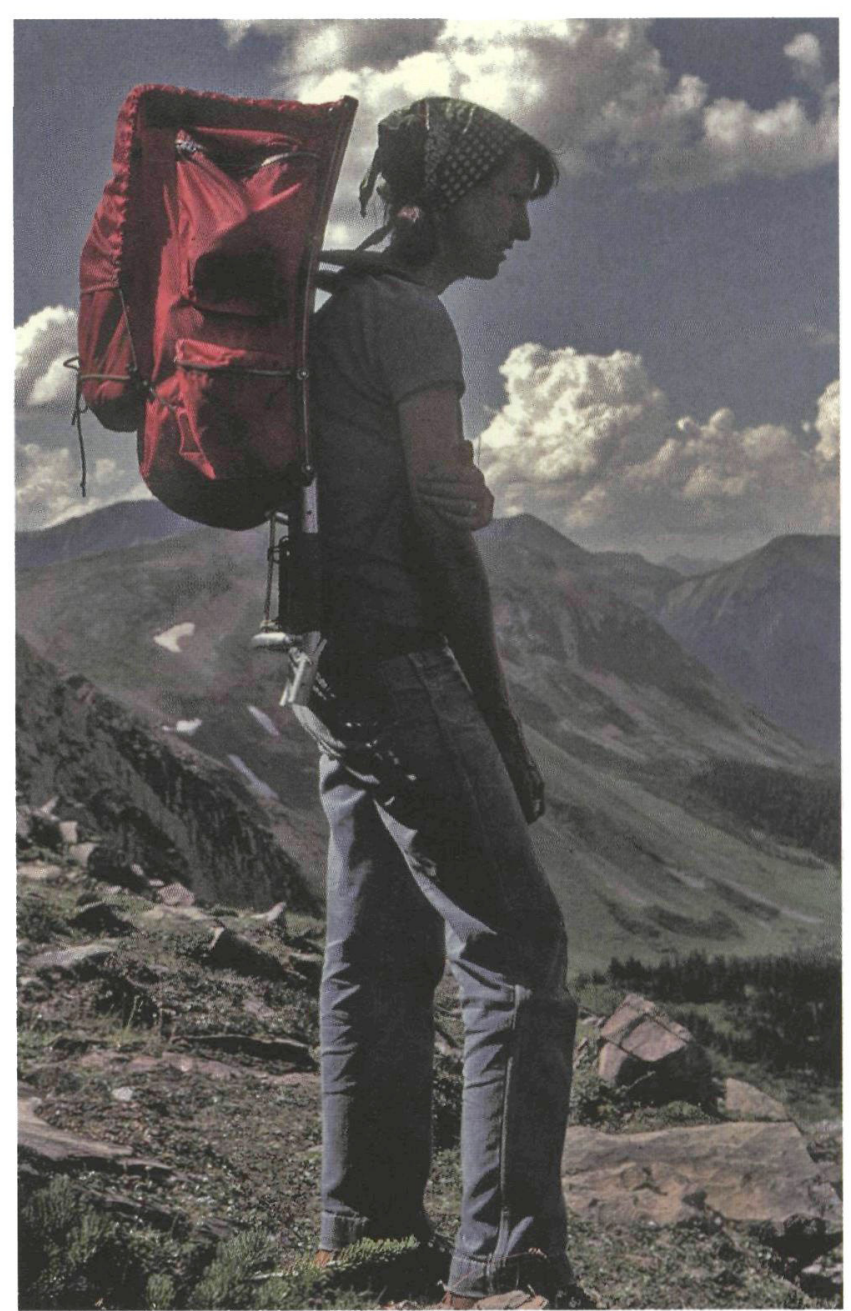

